\title{
Corn Ear Threshing Performance of Filler-Plate-Covered Threshing Cylinders
}

\author{
Valdas KINIULIS*, Dainius STEPONAVIČIUS**, Albinas ANDRIUŠIS***, \\ Aurelija KEMZŪRAITÉ****, Darius JOVARAUSKAS***** \\ *Institute of Agricultural Engineering and Safety, Aleksandras Stulginskis University, Studentu 15A, 53362 Akademija, \\ Kaunas distr., Lithuania, E-mail: valdas.kiniulis@gmail.com \\ **Institute of Agricultural Engineering and Safety, Aleksandras Stulginskis University, Studentu 15A, 53362 Akademija, \\ Kaunas distr., Lithuania, E-mail: Dainius.Steponavicius@asu.lt \\ ***Institute of Power and Transport Machinery Engineering, Aleksandras Stulginskis University, Studentu 15, 53362 \\ Akademija, Kaunas distr., Lithuania, E-mail: Albinas.Andriusis@asu.lt \\ ****Institute of Agricultural Engineering and Safety, Aleksandras Stulginskis University, Studentu 15A, 53362 Akademija, \\ Kaunas distr., Lithuania, E-mail: Aurelija.Kemzuraite@asu.lt \\ *****Institute of Agricultural Engineering and Safety, Aleksandras Stulginskis University, Studentu 15A, 53362 \\ Akademija, Kaunas distr., Lithuania,E-mail: darius.jovarauskas@gmail.com
}

cross $^{\text {ref }}$ http://dx.doi.org/10.5755/j01.mech.23.5.17389

\section{Introduction}

Corn Zea mays L. is among the most remarkable cereal species, which has great importance in the human diet and animal feed in the world. This is one of the most rapidly energy-accumulating agricultural plants [1]. Improving of crop yield harvesting and post-harvest processing results in increasing cultivated corn fields. European Union countries annually produce approximately 75 million tonnes of corn grain.

Harvesting of corn requires specific conditions and the fine-tuning of combine-harvester threshing apparatus. To ensure minimum loss during corn harvesting, the combine-harvester threshing apparatus, cleaning shoe and other mechanisms must undergo particular reconstructions and adjustments [2]. The performance of threshing apparatus depends on the feed rate, concave clearance and cylinder speed (linear speed of rasp bars) [3]. Setting wellbalanced technological parameters for adjustment of the threshing apparatus not only increases throughput of the combine harvester but also improves the quality indicators of the threshing process. This leads to reduced grain loss, reduced grain damage as well as improved grain separation through the concave [4].

The demands on throughput and harvesting quality of combine harvesters are still growing, so that improvements of the functional components are necessary [5]. Conventional threshing cylinders have an open construction. This type of cylinder construction has caused various problems during combine-harvester operations. For example, the impact of the open cylinder shape often results in cracking of the grain [6]. In addition, debris such as crop residue and soil ingested by the combine is frequently deposited in, and retained by, the rotating cylinder. As the mass of the debris increases, the operation of the cylinder falls out of balance, resulting in irregular engagement of the crop by the cylinder and potentially degrading the quality of grain separation. To increase grain separation and reduce grain damage, researchers suggested covering the spaces between adjacent rasp bars. For this purpose, some studies proposed using filler plates that have an evenly concave surface, whereas others proposed using filler plates with an angled profile [7]. It is considered that the shape of filler plates should be optimized. Considering the influence of threshing cylinder design on the airflow within the threshing apparatus, a potentially improved filler plate can be designed [8,9]. The airflow caused by cylinder rotation was sufficient to keep some part of the grains suspended in the air and even to be blown from the threshing apparatus [3]. In 2010, the German company CLAAS patented an enclosed threshing cylinder. In general, their cylinder has a solid, continuous cylindrical surface on which rasp bars are mounted for threshing the cereals. The enclosed cylinder is highly impervious to crops so that debris cannot accumulate inside the cylinder during operation. According to the authors of the patent, the enclosed cylinder is universally applicable because there is no longer a need to cover it with filler plates during corn threshing. However, results for the investigation of the threshing of corn ears have not been published.

Fitting the cylinder with filler plates was found to have a positive effect on wheat grain separation through the concave and also to reduce grain damage [6]. Experimental trials on a threshing cylinder with spaces between the cylinder rasp bars covered with filler plates showed a decrease in wheat grain damage from $2.01 \%$ to $0.17 \%$ [7]. Researchers considered the main reason for the reduction in grain damage to be that when threshing with an enclosed construction cylinder, grain separation increases in the frontal part of the threshing apparatus, i.e. in front of the concave. Moreover, researchers noted that wheat grain separation using an enclosed construction cylinder might be intensified by increasing the cylinder speed [10]. It is considered that the shape of filler plates appropriate for corn ear threshing should be optimized [9].

The hypothesis in the present research was that covering the spaces between the cylinder rasp bars has a positive effect on corn grain damage during threshing (the percentage of damaged grain decreases) and on grain separation through the concave (the percentage of threshed grains passed onto the straw walkers decreases). 
The aim of this work was to determine the influence of threshing cylinder filler plates on indicators of the corn ear threshing (shelling) process.

\section{Materials and methods}

The experimental method has been applied to the study. It is time-consuming method considering a theoretical analysis of corn ears threshing process usually involves a series simplification [11]. The random motion of the corn ears in the threshing space in most cases leads to a certain difference between the numerical results and experimental data [12].

When threshing corn ears, the following three technological processes take place inside the threshing crescent: corn ears are threshed, i.e., grains are separated from ear cobs; threshed grains are separated through the mass being threshed and the concave grates; and the entire mass being threshed is transported over the surface of the concave toward the straw walkers. Grains remaining on cobs that are passed onto the straw walkers are considered to be the threshing loss $N$. The tolerable level $(0.3 \%$ of yield) of threshing loss for combines in corn should not be exceeded [3, 13]. The proportion of threshed grains not separated through the concave are considered to be the grain separation loss $K$. Petkevichius et al. [3] stated that separation loss should not exceed $20 \%$ of grain feed rate by corrected adjustment of threshing apparatus; i.e. less than $20 \%$ of the threshed grains should be thrown to straw walker.

During the experimental trials, threshing performance was measured by means of the following indicators: threshing loss (unthreshed grains remaining on cobs), grain separation and grain separation intensity, proportion of grains passed onto the straw walkers and proportion of damaged grain.

\subsection{Threshing and grain separation losses}

Experimental trials were carried out in 2013-2015 at the Laboratory-Experimental Station for Investigation Technological Processes of Agricultural Machinery using a stationary tangential single-cylinder threshing unit (Fig. 1) comprised of the following components. A belt feeder 1 (10 $\mathrm{m}$ in length and $1.2 \mathrm{~m}$ in width) was used for feeding corn ears into the threshing unit. A tangential threshing cylinder 3 ( $1.2 \mathrm{~m}$ in width and $0.6 \mathrm{~m}$ in diameter) with eight rasp bars attached to it was wrapped in the concave 4 (wrapping angle of $146^{\circ}$ ). Threshed and unseparated grains and impurities (e.g. leaves and cobs) were diverted to the collection tank 10 by the back beater 6 . Portions of the threshed grain-chaff separated through individual sections of the concave were collected in tanks 7,8 and 9.

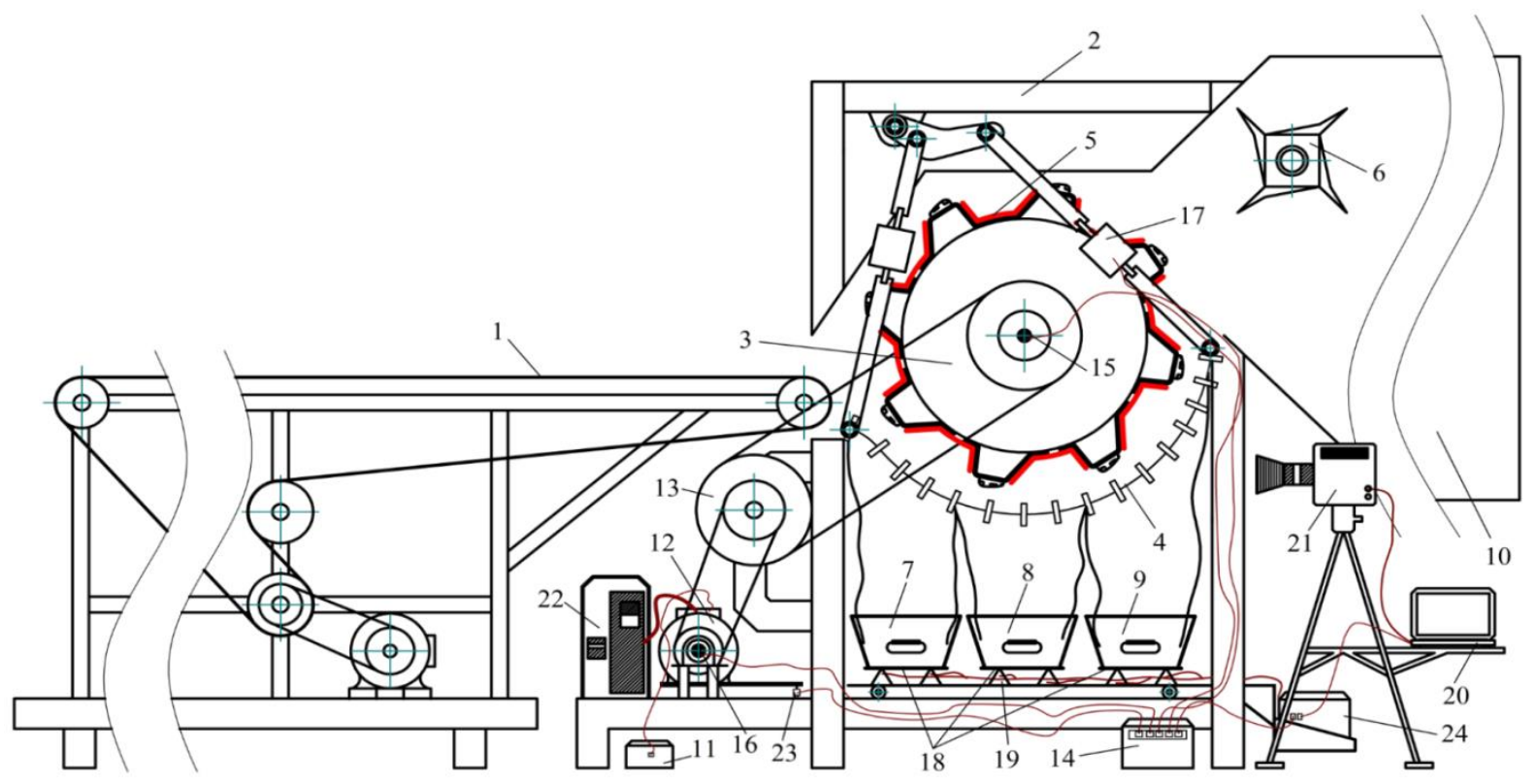

Fig. 1 Schematic of the stationary unit used for threshing corn ears: 1 - flat belt feeder; 2 - frame of the stationary threshing unit; 3 - threshing cylinder; 4 - concave; 5 - threshing cylinder filler plates; 6 - back beater; 7, 8, 9-tanks for collecting grains separated through individual sections of the concave; 10 - collection tank; 11 - device for measuring electric power; 12 -electric motor; 13 -transitional pulley; 14 -amplifier unit with power supply; 15,16 - optical encoders of the electric motor and threshing cylinder rotation speed; 17 - force sensor at the end of the concave; 18 - weighing scale base units with sensors (3 pieces); 19 - tensoresistor load sensors; 20 - computer; 21 -high-speed camera; 22 -variable frequency drive (VFD) controller; 23 -motor torque sensor and 24 - measurement unit with power supply

For rotation of the working components of the threshing unit, a $15 \mathrm{~kW}$ electric motor was used. Threshing cylinder (Fig. 2) speed was fixed $\left(450 \mathrm{~min}^{-1}\right)$ using a variable frequency drive (VFD) controller Delta VFD-C2000 SERIES and belt drive. The speed of the cylinder shaft rotation was measured using an optical encoder 15.
Investigation was carried out using a threshing apparatus equipped with a concave with surface area of $0.96 \mathrm{~m}^{2}$, for which the active separation area was equal to $69.19 \%$. Before starting the trials, the clearance between the cylinder rasp bars and the concave crossbars was set to $34 \mathrm{~mm}$ in the front, $26 \mathrm{~mm}$ in the middle and $22 \mathrm{~mm}$ at the end of concave. 
Corn ears of the Rodni species were threshed in the threshing unit. The ears were at physiological maturity and had a grain moisture content of $30.49 \pm 0.60 \%$. The moisture content of the cobs was $54.85 \pm 1.31 \%$ and that of the ear-covering leaves was $27.51 \pm 2.41 \%$. After being weighed on a digital weighing scale $C A S D B-1 H$ (maximum load $60 \pm 0.02 \mathrm{~kg}$, minimum load $400 \pm 20 \mathrm{~g}$ ), a $7-\mathrm{m}$ length flat belt feeder was evenly covered with corn ears, which were fed into the tangential threshing unit at a speed of $1.0 \mathrm{~m} \mathrm{~s}^{-1}$. Corn ear threshing trials were performed at feed rates ranging from $4 \mathrm{~kg} \mathrm{~s}^{-1}$ to $12 \mathrm{~kg} \mathrm{~s}^{-1}$.

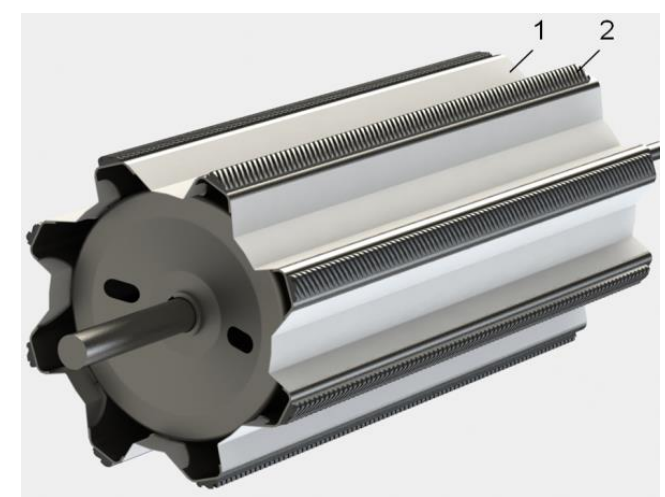

Fig. 2 Threshing cylinder with gap-closing filler plates: 1 - filler plate and 2 - rasp bar

Threshing loss $N$ was determined from the corn cob pieces with grains that were collected in tank 10. In the laboratory, grains that had been hand-shelled from cobs were weighed and the grain loss $\%$ was estimated.

For the investigation of grain separation through concave $A$, the surface of the concave was divided into three sections (Fig. 3). Threshed grain separated through Sections 1, 2 and 3 of the concave were collected in tanks 7,8 and 9 , respectively. They were weighed using a digital weighing scale, which included the three components of base unit 18 (four resistive sensors each) and amplifier unit 24 (Fig. 1). This system, computer 20, and the created software ThreshLab were used to record real-time changes in the weights of the tanks.

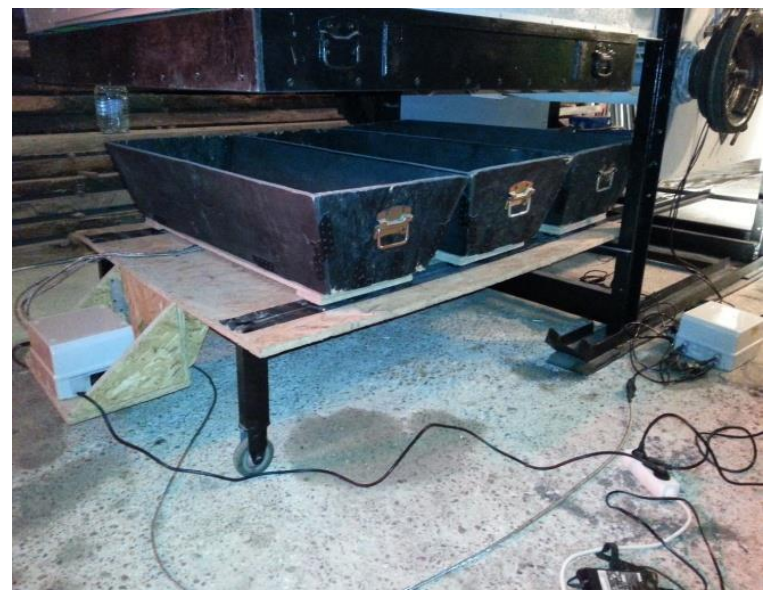

Fig. 3 Digital weighing scale tanks, bases with sensors and amplifier unit on the frame

Using dates supplied by measurement unit 24, computer 20, and ThreshLab, the mean value of the weight signal at pre-set time intervals $(30 \mathrm{~ms})$ was calculated. For this purpose, measurements were taken at a higher rate (every $2 \mathrm{~ms}$ ), the date sample of the pre-set size (of 5 values) was collected, and the average was calculated for each of the tanks on the weighing scale (Fig. 3). The weight limit per tank was $50 \mathrm{~kg}$, the sensitivity was $0.01 \mathrm{~kg}$, the resolution was $48.9 \mathrm{~g}$, and the error was below $3 \%$.

Threshed grain, grain not separated through the concave and material other than grain (MOG) were collected in tank the 10. After grain from the grain-impurities mixture had been separated, grain separation loss $K$ was determined by air flow using a Petkus K-293 device (Petkus, Germany).

\subsection{Intensity of grain separation through the concave}

Due to the above-mentioned weighing system installed beneath the concave of the threshing unit, threshed grain separation intensity through the concave at each of its three sections $\left(k_{1}, k_{2}\right.$ and $k_{3}$, in $\left.\mathrm{kg} \mathrm{s}^{-1}\right)$ and through the entire concave $\left(k\right.$, in $\left.\mathrm{kg} \mathrm{s}^{-1}\right)$ can be measured at very small time intervals (i.e., every $30 \mathrm{~ms}$ ) during the threshing process.

The total grain separation through each section of the concaves $S_{1}, S_{2}, S_{3}$ and entire concave $S_{\Sigma}$, can be approximated at separation time $t$ using a linear function:

$$
S_{\Sigma}=k t-b
$$

where: $k$ and $b$ are coefficients of the equation of the straight line.

The slope coefficient $k$ is related to grain separation intensity as follows:

$$
\begin{aligned}
& k=\operatorname{tg} \alpha=\frac{d S_{\Sigma}}{d t}, \\
& \frac{d S_{\Sigma}}{d t}=\frac{d S_{1}}{d t}+\frac{d S_{2}}{d t}+\frac{d S_{3}}{d t},
\end{aligned}
$$

where $\alpha$ is the angle between the straight line and the abscissa axis.

\subsection{Grain damage}

To determine grain damage, three $200 \mathrm{~g}$ samples were collected from tanks 7,8 and 9 and collection tank 10 (Fig. 1). Samples collected from the different tanks were placed into separate bags marked with the respective number and the various technological parameters. In the laboratory, three $100 \mathrm{~g}$ samples were taken from each grain bag. Mechanically-damaged grains were separated from each sample and weighed, and the average percentage of grain damage was calculated. Furthermore, 25 samples of threshed-out corn ear were randomly sampled from collection tank 10. The length of each was measured and the average length was calculated.

\subsection{Grain cleanliness}

Cleanliness was measured by determining the foreign-matter content, i.e., MOG. The grain-impurities mixture fell through individual sections of the concave to tanks 7, 8 and 9 (Fig. 1) and was separated by air flow using 
the Petkus $K$-293 device. The separated impurities were then weighed.

\subsection{Average length of crushed cobs}

At the end of each trial, 50 cobs were taken from collection tank 10 (Fig. 1) and their average length was measured using a calliper.

\subsection{Design of threshing cylinder}

Initially, corn ear threshing experiments were performed using an open (conventional) threshing cylinder. For the purposes of further comparative trials, stainlesssteel filler plates of three different shapes were produced, each with a thickness of $1.5 \mathrm{~mm}$ and a mass of $2.54 \pm 0.21 \mathrm{~kg}$ (Fig. 4). They were attached by means of steel rivets. There were eight identical filler plate pieces in one set. To investigate corn ear threshing, the three sets considered were: Filler Plate I (FP-I) with a shape resembling the standard shape of the cylinder spaces between adjacent rasp bars (Fig. 4a); Filler Plate II (FP-II) with a working plane at an angle of $55^{\circ}$ to the radius of the cylinder (Fig. 4, b); and Filler Plate III (FP-III) with a working plane at an angle of $36^{\circ}$ to the radius of the cylinder (Fig. 4, c).
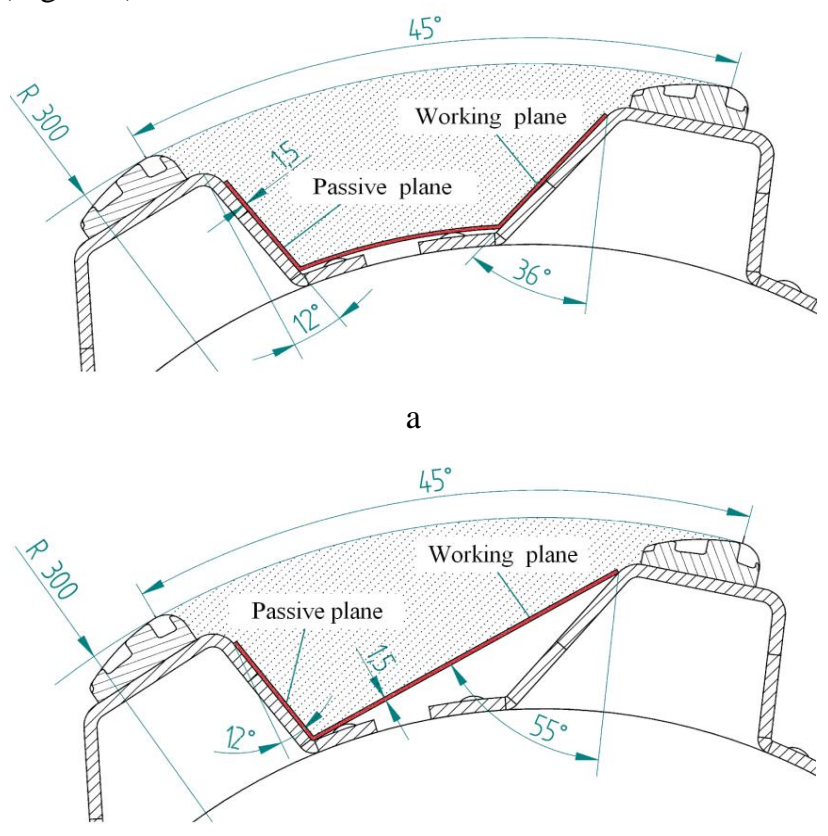

b

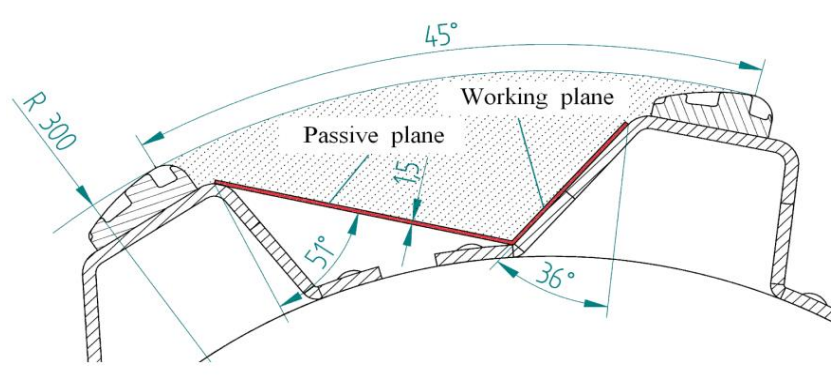

c

Fig. 4 Portion of the threshing cylinder with spaces between rasp bars covered by FP-I $(a)$, FP-II $(b)$ and FP-III $(c)$ [9]
Covering the threshing cylinder with set FP-I increased its mass, resulting in an increased moment of inertia from $8.49 \mathrm{~kg} \mathrm{~m}^{2}$ to $9.62 \mathrm{~kg} \mathrm{~m}^{2}$. With the open threshing cylinder, a cross-sectional area of one space between the rasp bars amounted to $95.94 \mathrm{~cm}^{2}$, whereas the same crosssection area amounted to $87.05 \mathrm{~cm}^{2}$ after the FP-I was covered (Fig. 4, a), i.e. the area was reduced by $9.27 \%$. By covering the threshing cylinder with set FP-II, the crosssectional area of one space between the rasp bars was found to decrease from $95.94 \mathrm{~cm}^{2}$ to $79.13 \mathrm{~cm}^{2}$, i.e. a $17.52 \%$ reduction. The passive surface of the threshing cylinder filler plate formed a $12^{\circ}$ angle to the cylinder radius (Fig. 4, b). Covering the threshing cylinder with set FP-III caused the cross-sectional area of one space between the rasp bars to decrease from $95.94 \mathrm{~cm}^{2}$ to $75.69 \mathrm{~cm}^{2}$, i.e. a $21.12 \%$ reduction (Fig. $4, \mathrm{c}$ ).

Each trial was repeated three times. Measurement data were assessed by computing the confidence interval of the mean at $95 \%$ probability.

\section{Results and discussion}

\subsection{Threshing and grain separation losses}

Feed rate is one of the most important factors that influences combine harvester performance [14]. Analysis of findings and results obtained through investigation showed that at a $4 \mathrm{~kg} \mathrm{~s}^{-1}$ feed rate to the open threshing cylinder, majority of the grain was separated through Section 1 of the concave $(39.3 \%)$, whereas that separated through Section 2 was $27.1 \%$ and that through Section 3 was $21.7 \%$ (Fig. 5). In this case, the proportion of grain passed onto the straw walkers $K$ amounts for as little as $11.7 \%$ and the threshing loss $N$ was $0.2 \%$.

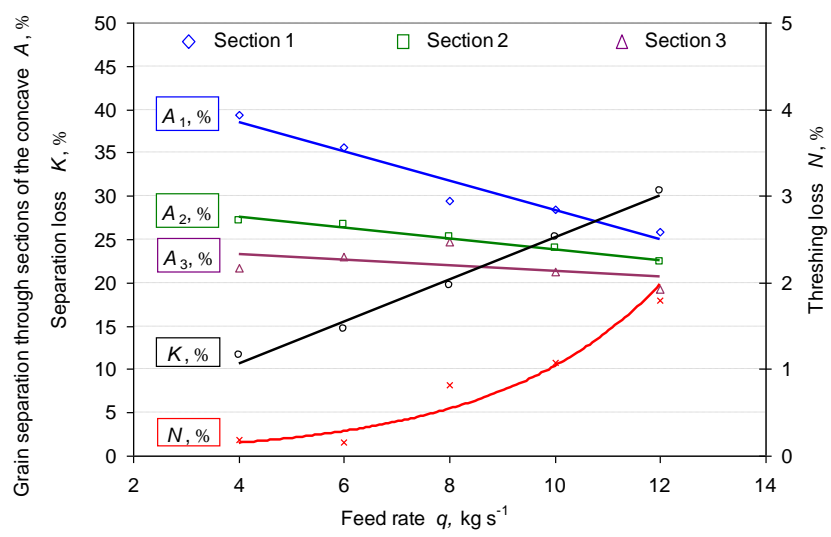

Fig. 5 Effect of corn ear feed rate $q$ on (i) grain separation $A$ through individual sections of the concave and (ii) threshing loss $N$ when the threshing cylinder featured open spaces between the rasp bars:

$$
\begin{aligned}
& A_{1}=-1.701 q+45.34 ; R^{2}=0.94 ; \\
& A_{2}=-0.614 q+29.98 ; R^{2}=0.97 ; \\
& A_{3}=-0.323 q+24.58 ; R^{2}=0.70 ; \\
& K=2.430 q+0.944 ; R^{2}=0.98 ; \\
& N=0.041 e^{0.323 q} ; R^{2}=0.87
\end{aligned}
$$

An increase in feed rate caused grain separation to decrease through all the sections of the concave (Fig. 5); at a feed rate of $12 \mathrm{~kg} \mathrm{~s}^{-1}$, grain separation decreased to 
$25.9 \%, 22.3 \%$ and $19.3 \%$ through Sections 1, 2 and 3 of the concave, respectively. As a result, the proportion of grain passed onto the straw walkers $(30.6 \%)$ exceeded the grain separation through individual sections of the concave, while the threshing loss increased to $1.8 \%$. It is worth emphasizing that the proportion of non-threshed grains increased exponentially with an increase in feed rate.

In this study the threshing loss is relatively high as compared to Paulsen et al. [13] combine harvesters investigations in corn harvesting. The reason for this difference is that in the combine harvester cobs with unthreshed grains were returned to rethreshing.

Investigation of corn ear threshing using the threshing cylinder covered with set FP-I showed that at a feed rate of $4 \mathrm{~kg} \mathrm{~s}^{-1}, 33.7 \%$ of grains were separated through Section 1 of the concave, while $27.4 \%$ and $21.6 \%$ were separated through Sections 2 and 3, respectively (Fig. 6). In this case, the proportion of grain passed onto the straw walkers amounted to $16.8 \%$, with a threshing loss of $0.44 \%$. An increase in feed rate to $12 \mathrm{~kg} \mathrm{~s}^{-1}$ caused grain separation to decrease to $25.3 \%$ and $21.2 \%$ through Sections 1 and 2 of the concave, respectively. However, grain separation through Section 3 increased with increasing feed rate; at a feed rate of $12 \mathrm{~kg} \mathrm{~s}^{-1}$, it reached $23.4 \%$. As a result, the proportion of grain passed onto the straw walkers decreased to $28.3 \%$, i.e. a reduction of 2.3 percentage points in comparison with that for the open threshing cylinder. Threshing loss also decreased to $1.75 \%$.

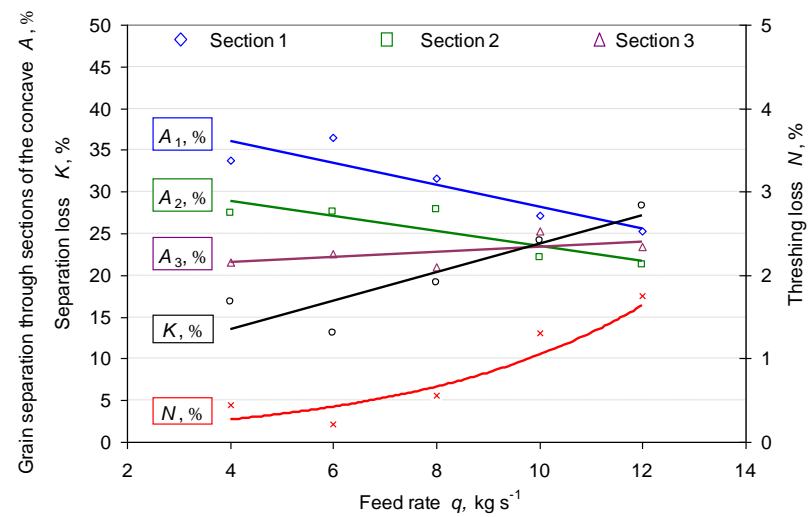

Fig. 6 Effect of corn ear feed rate $q$ on (i) grain separation $A$ through individual sections of the concave and (ii) threshing loss $N$ when the threshing cylinder was covered with set FP-I:

$$
\begin{aligned}
& A_{1}=-1.313 q+41.34 ; R^{2}=0.82 ; \\
& A_{2}=-0.895 q+32.42 ; R^{2}=0.75 ; \\
& A_{3}=0.316 q+20.22 ; R^{2}=0.75 ; \\
& K=1.705 q+6.64 ; R^{2}=0.81 ; \\
& N=0.108 e^{0.226 q} ; R^{2}=0.78
\end{aligned}
$$

When the threshing cylinder was covered with set FP-II at a feed rate of $4 \mathrm{~kg} \mathrm{~s}^{-1}, 40.4 \%$ of grains were separated through Section 1 of the concave (Fig. 7). In comparison with the threshing cylinder covered with set FP-I, $A_{1}$ increased by 6.7 percentage points. The proportion of grain passed onto the straw walkers amounted to $11 \%$ and the threshing loss was $0.49 \%$. An increase in feed rate to $12 \mathrm{~kg} \mathrm{~s}^{-1}$ caused grain separation through Section 1 of the concave to halve (to 20.6\%). However, considering the grain separation through Section $2(25.8 \%)$ and Section 3
$(26.1 \%)$ at a feed rate of $12 \mathrm{~kg} \mathrm{~s}^{-1}$, it is apparent that the threshing cylinder covered with set FP-II was more effective because the proportion of grain passed onto the straw walkers decreased to $25.9 \%$. The decrease in threshing loss was negligible $(1.66 \%)$ when the threshing cylinder was covered with set FP-II.

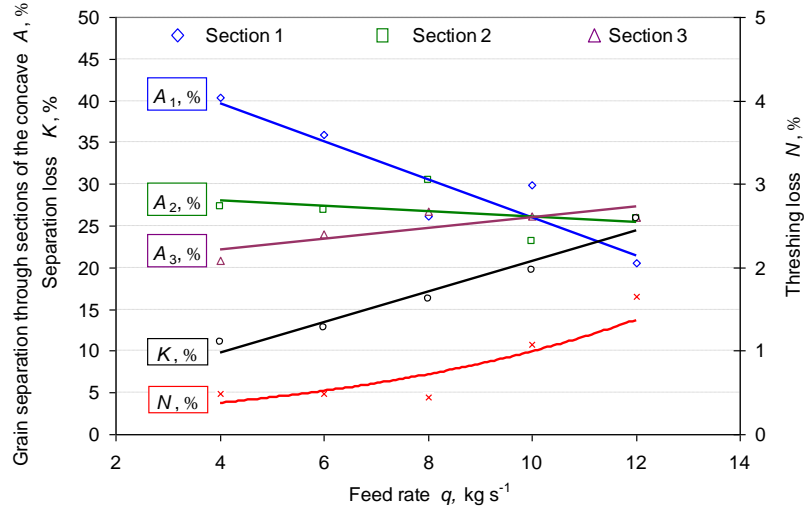

Fig. 7 Effect of corn ear feed rate $q$ on (i) grain separation $A$ through individual sections of the concave and (ii) threshing loss $N$ when the threshing cylinder was covered with set FP-II:

$$
\begin{aligned}
& A_{1}=-2.28 q+48.82 ; R^{2}=0.85 ; \\
& A_{2}=-0.336 q+29.40 ; R^{2}=0.77 ; \\
& A_{3}=0.635 q+19.65 ; R^{2}=0.75 ; \\
& K=1.835 q+2.47 ; R^{2}=0.96 ; \\
& N=0.197 e^{0.162 q} ; R^{2}=0.77
\end{aligned}
$$

Analysis of results obtained at a $4 \mathrm{~kg} \mathrm{~s}^{-1}$ feed rate to the threshing cylinder covered with set FP-III showed that grain separation through Section 1 of the concave increased to $41.4 \%$ (Fig. 8).

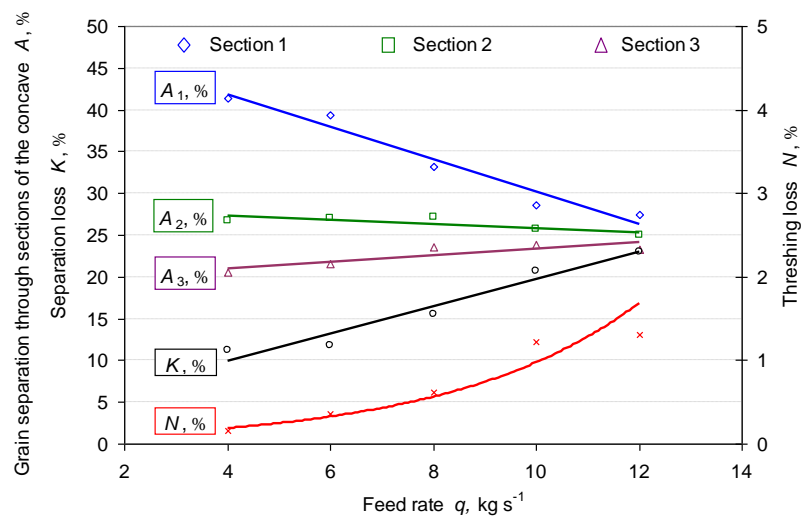

Fig. 8 Effect of corn ear feed rate $q$ on (i) grain separation $A$ through individual sections of the concave and (ii) threshing loss $N$ when the threshing cylinder was covered with set FP-III:

$$
\begin{aligned}
& A_{1}=-1.935 q+49.49 ; R^{2}=0.96 ; \\
& A_{2}=-0.247 q+28.27 ; R^{2}=0.77 ; \\
& A_{3}=0.390 q+19.43 ; R^{2}=0.73 ; \\
& K=1.633 q+3.35 ; R^{2}=0.95 ; \\
& N=0.0624 e^{0.275 q} ; R^{2}=0.94
\end{aligned}
$$

Compared with the threshing cylinder covered with set FP-I, grain separation increased by 7.7 percentage 
points. Grain separation through the other two sections of the concave remained similar to that observed for the threshing cylinder covered with set FP-II. Grain separation through Sections 2 and 3 of the concave was $26.8 \%$ and $20.5 \%$, respectively. In the latter case, the proportion of grain passed onto the straw walkers amounted to $11.2 \%$ and the proportion of non-threshed grain was $0.16 \%$. As in previous cases, an increase in feed rate to $12 \mathrm{~kg} \mathrm{~s}^{-1}$ caused grain separation to decrease through Section 1 of the concave (to $27.5 \%$ ), which is slightly higher those that for threshing cylinders featuring other space shapes between the rasp bars. In this particular case, the grain separation through Section 2 of the concave decreased to $24.9 \%$, and through Section 3 it increased to $23.2 \%$. The proportion of grain passed onto the straw walkers amounted to $23.0 \%$ but did not exceed the grain separation through individual sections of the concave. Threshing loss decreased slightly (to $1.31 \%$ ) in comparison with those of threshing cylinders featuring other space shapes between the rasp bars.

\subsection{Intensity of grain separation through the concave}

Air flow investigations of threshing cylinders with different designs of the spaces between the rasp bars revealed a positive effect of filler plates on air flow movement in the cylinder-to-concave clearance. This was followed by trials of corn ear threshing performance [11]. These were undertaken to determine the influence of the form of the cylinder spaces between the rasp bars on threshing performance. Corn ear threshing trials that involved the open threshing cylinder showed that at a feed rate of $4 \mathrm{~kg} \mathrm{~s}^{-1}$, grain separation intensity $k_{1}$ in Section 1 of the concave was $1.36 \mathrm{~kg} \mathrm{~s}^{-1}$, while in Section 2 it was $k_{2}=0.93 \mathrm{~kg} \mathrm{~s}^{-1}$ and in Section 3 it was $k_{3}=0.74 \mathrm{~kg} \mathrm{~s}^{-1}$ (Fig. 9). Increasing the corn ear feed rate caused the grain separation intensity to increase consistently in all three sections of the concave. At a corn ear feed rate of $12 \mathrm{~kg}$ $\mathrm{s}^{-1}$, the separation intensity in Section 1 of the concave reached $2.46 \mathrm{~kg} \mathrm{~s}^{-1}$, while it increased to $2.10 \mathrm{~kg} \mathrm{~s}^{-1}$ and $1.79 \mathrm{~kg} \mathrm{~s}^{-1}$ in Sections 2 and 3, respectively.

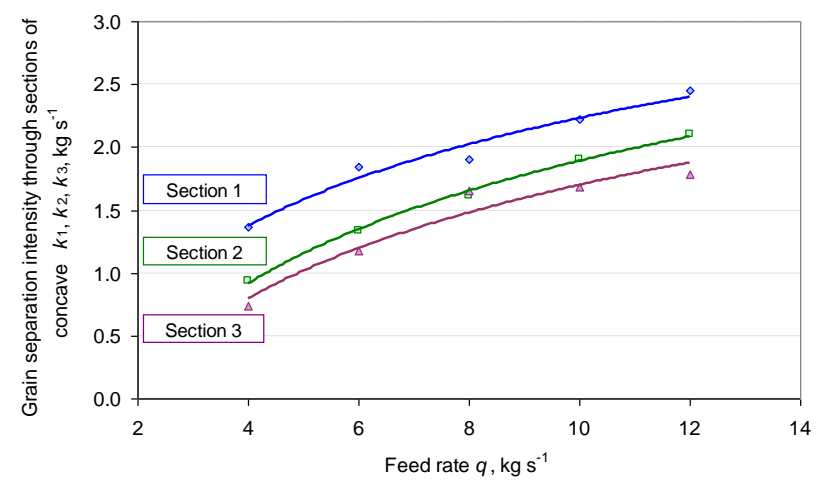

Fig. 9 Effect of corn ear feed rate $q$ on grain separation intensity through individual sections of the concave with open cylinder spaces between the rasp bars:

Section 1: $k_{1}=0.937 \ln (q)-0.073 ; R^{2}=0.69$;

Section 2: $k_{2}=1.065 \ln (q)-0.562 ; R^{2}=0.99$;

Section 3: $k_{3}=0.986 \ln (q)-0.571 ; R^{2}=0.94$

When the threshing cylinder was covered with set FP-I, at higher feed rates of mass to be threshed, i.e.,
$10 \mathrm{~kg} \mathrm{~s}^{-1}$ and $12 \mathrm{~kg} \mathrm{~s}^{-1}$, a significant increase in grain separation intensity through Section 3 of the concave was observed (Fig. 10).

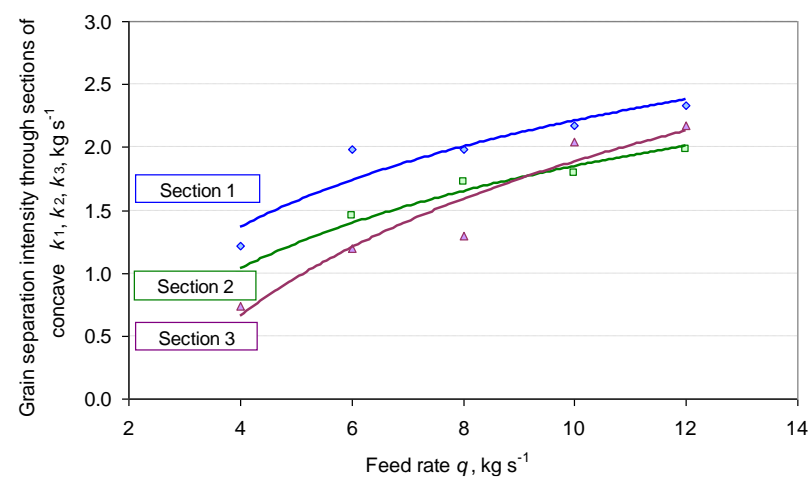

Fig. 10 Effect of corn ear feed rate $q$ on grain separation intensity through individual sections of the concave when the threshing cylinder was covered with set FP-I:

Section 1: $k_{1}=0.926 \ln (q)-0.077 ; R^{2}=0.89$;

Section $2: k_{2}=0.891 \ln (q)-0.203 ; R^{2}=0.97$;

Section 3: $k_{3}=1.339 \ln (q)-1.197 ; R^{2}=0.92$

At a corn ear feed rate of $10 \mathrm{~kg} \mathrm{~s} \mathrm{~s}^{-1}, k_{3}$ was $2.05 \mathrm{~kg} \mathrm{~s}^{-1}$, whereas at a feed rate of $12 \mathrm{~kg} \mathrm{~s}^{-1}$ it was $2.24 \mathrm{~kg} \mathrm{~s}^{-1}$. This is approximately a $0.4 \mathrm{~kg} \mathrm{~s}^{-1}$ increase in separation intensity from that for the threshing cylinder with open spaces between the rasp bars.

When the threshing cylinder was covered with set FP-II (Fig. 11) and a feed rate of $4 \mathrm{~kg} \mathrm{~s}^{-1}$ was used, no significant differences were observed in grain separation intensity through sections of the concave when compared with previously discussed threshing cylinders (Figs. 9 and $10)$.

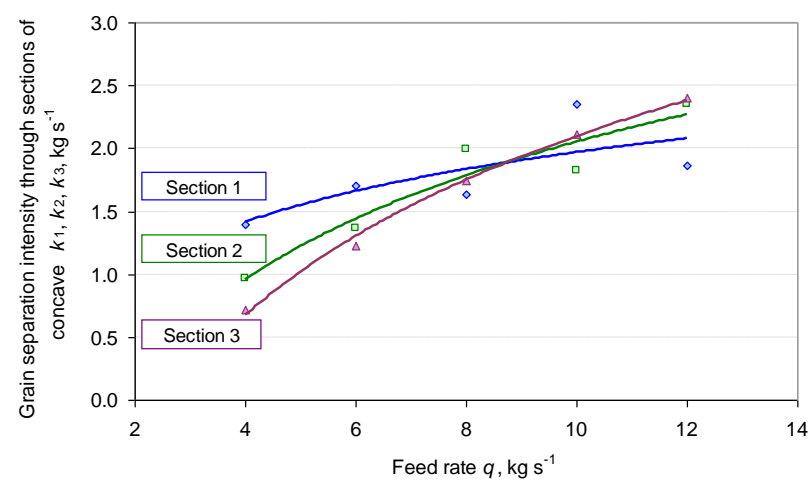

Fig. 11 Effect of corn ear feed rate $q$ on grain separation intensity through individual sections of the concave when the threshing cylinder was covered with set FP-II:

Section 1: $k_{1}=0.437 \ln (q)-0.828 ; R^{2}=0.83$;

Section 2: $k_{2}=1.197 \ln (q)-0.704 ; R^{2}=0.91$;

Section 3: $k_{3}=1.554 \ln (q)-1.482 ; R^{2}=0.99$

However, at higher feed rates of mass to be threshed, a decrease in grain separation intensity through Section 1 of the concave was observed. At a feed rate of $10 \mathrm{~kg} \mathrm{~s}^{-1}$, grain separation intensity $k_{1}$ decreased to 
$1.92 \mathrm{~kg} \mathrm{~s}^{-1}$, and at feed rate of $12 \mathrm{~kg} \mathrm{~s}^{-1}$, it decreased to $1.87 \mathrm{~kg} \mathrm{~s}^{-1}$. However, under the same conditions, grain separation intensity through Sections 2 and 3 of the concave were $2.41 \mathrm{~kg} \mathrm{~s}^{-1}$ and $2.35 \mathrm{~kg} \mathrm{~s}^{-1}$, respectively. This indicates that at a feed rate of $12 \mathrm{~kg} \mathrm{~s}^{-1}$, grain separation intensity through Section 1 of the concave decreased by $0.59 \mathrm{~kg} \mathrm{~s}^{-1}$, while through Sections 2 and 3 it increased by $0.31 \mathrm{~kg} \mathrm{~s}^{-1}$ and $0.56 \mathrm{~kg} \mathrm{~s}^{-1}$, respectively, when compared with those for the open threshing cylinder.

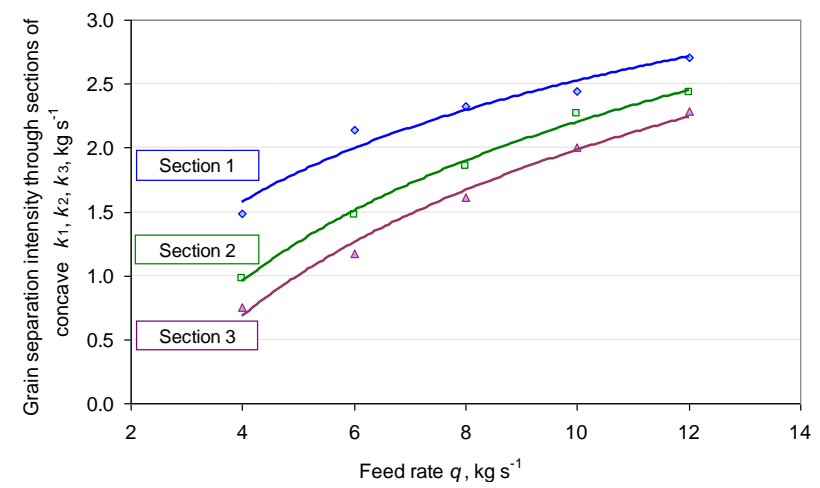

Fig. 12 Effect of corn ear feed rate $q$ on grain separation intensity through individual sections of the concave when the threshing cylinder was covered with set FP-III:

Section 1: $k_{1}=1.036 \ln (q)-0.073 ; R^{2}=0.96$;

Section $2: k_{2}=1.361 \ln (q)-0.562 ; R^{2}=0.99$;

Section 3: $k_{3}=1.419 \ln (q)-0.571 ; R^{2}=0.99$

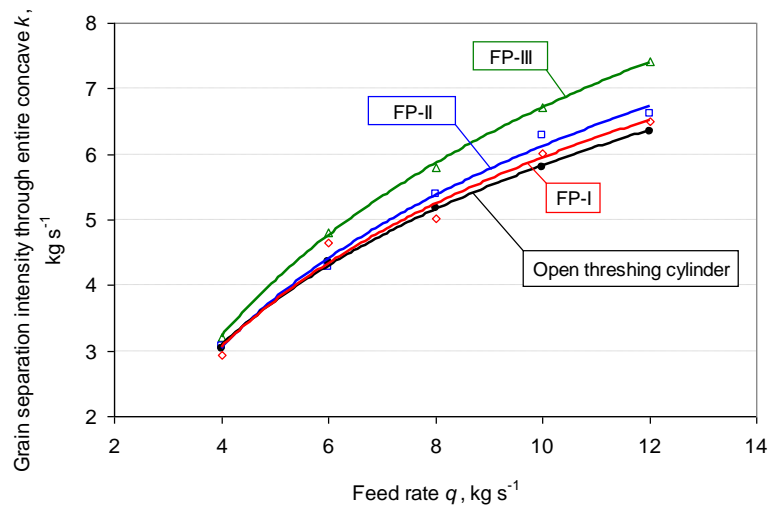

Fig. 13 Effect of corn ear feed rate $q$ on grain separation intensity $k$ through the concave:

Open threshing cylinder: $k=2.988 \ln (q)-1.060$; $R^{2}=0.99$;

$$
\begin{array}{ll}
\text { FP-I: } k=3.156 \ln (q)-1.323 ; & R^{2}=0.98 ; \\
\text { FP-II: } k=3.357 \ln (q)-1.611 ; & R^{2}=0.99 ; \\
\text { FP-III: } k=3.816 \ln (q)-2.077 ; & R^{2}=0.99
\end{array}
$$

During the threshing trials that involved the threshing cylinder covered with set FP-III and when the feed rate was increased from $4 \mathrm{~kg} \mathrm{~s}^{-1}$ to $12 \mathrm{~kg} \mathrm{~s}^{-1}$, an obvious increase in separation intensity was observed in Section 1 of the concave (Fig. 12). At a feed rate of $4 \mathrm{~kg} \mathrm{~s}^{-1}$, the intensity of grain separation through the concave $k_{1}$ increased to $1.48 \mathrm{~kg} \mathrm{~s}^{-1}$, which is $0.12 \mathrm{~kg} \mathrm{~s}^{-1}$ higher than that for the open threshing cylinder. Grain separation in- tensity through Section 1 of the concave increased steadily with increasing feed rate. Increasing the feed rate to $12 \mathrm{~kg} \mathrm{~s}^{-1}$ caused the separation intensity $k_{1}$ to reach $2.70 \mathrm{~kg} \mathrm{~s}^{-1}$, which is $0.24 \mathrm{~kg} \mathrm{~s}^{-1}$ higher than that for the open threshing cylinder.

When investigating the effect of the shape of the spaces between the rasp bars on grain separation intensity through each of the three sections of the concave $k$, FP-III was observed to have an advantage over the other shapes under consideration (Fig. 13). This difference was not significant at a feed rate of $4 \mathrm{~kg} \mathrm{~s}^{-1}$, which amounts to only $0.2 \mathrm{~kg} \mathrm{~s}^{-1}$. However, with an increase in feed rate, this difference increased steadily. At a feed rate of $12 \mathrm{~kg} \mathrm{~s}^{-1}$, the difference in grain separation intensity between FP-III and the case with open spaces between the rasp bars was $0.93 \mathrm{~kg} \mathrm{~s}^{-1}$. This difference in separation intensity was further calculated on a per hour basis, resulting in the conclusion that using a threshing cylinder covered with FP-III enabled the separation of an additional $3348 \mathrm{~kg}$ grains through the concave.

\subsection{Grain damage}

Grain damage depends upon the moisture content of the threshed crop mass, upon the technological parameters of the threshing mechanism and also upon the crop mass flow [4]. The most threshing research has shown that high cylinder speed is the main factor causing corn grain damage $[3,15,16]$. There is a limited amount of research conducted on the effect of cylinder filler plate on corn grain damage.

Investigation showed that a maximum grain damage of $S=7.2 \%$ was found in the portion of grain passed onto the straw walkers (Fig. 14) when a feed rate of $6 \mathrm{~kg} \mathrm{~s}^{-1}$ was set and the open threshing cylinder was used for corn ear threshing. Using the threshing cylinder covered with set FP-III resulted in grain damage of as little as $4.9 \%$, which is 2.3 percentage points lower than that for the open cylinder. Analysis of grains separated through individual sections of the concave revealed no significant difference in grain damage in relation to the shape of the threshing cylinder filler plates.

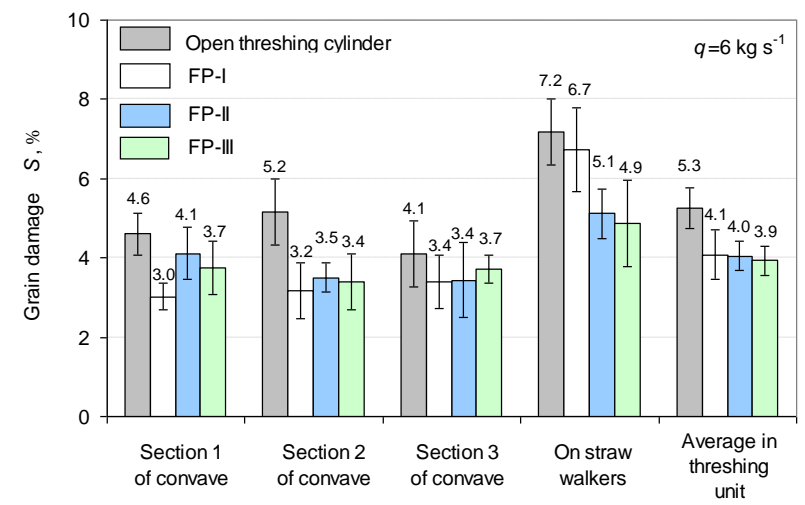

Fig. 14 Percentage of grains damaged $S$ at a corn ear feed rate of $6 \mathrm{~kg} \mathrm{~s}^{-1}$

To summarize the grain damage data regarding the entire threshing unit, the least grain damage (3.9\%) was found to occur in the threshing cylinder covered with set FP-III $\left(q=6 \mathrm{~kg} \mathrm{~s}^{-1}\right)$. 


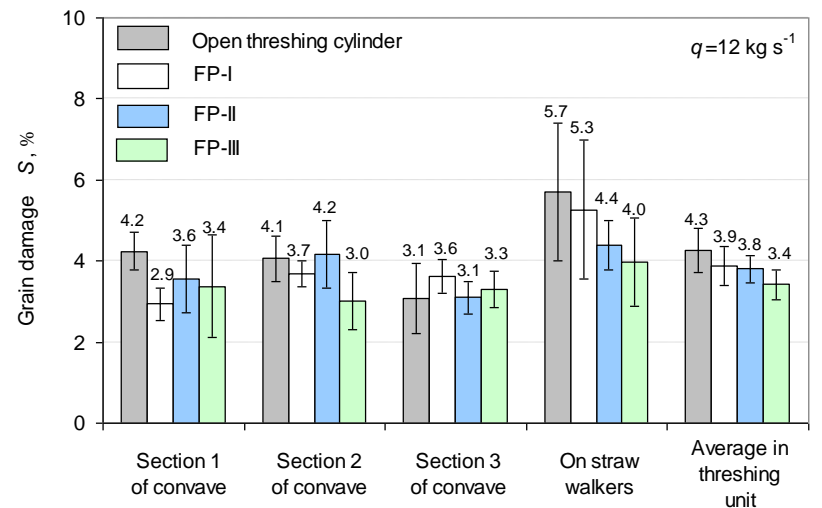

Fig. 15 Percentage of grains damaged $S$ at a corn ear feed rate of $12 \mathrm{~kg} \mathrm{~s}^{-1}$

Following an increase in a feed rate to $12 \mathrm{~kg} \mathrm{~s}^{-1}$ (Fig. 15), trends in grain damage remained very similar to those at the $6 \mathrm{~kg} \mathrm{~s}^{-1}$ feed rate; no significant differences in grain damage were observed between feed rates of $6 \mathrm{~kg} \mathrm{~s}^{-1}$ and $12 \mathrm{~kg} \mathrm{~s}^{-1}$. Meanwhile, in winter wheat harvesting increase of the combine harvester feed rate caused the decrease of the grain damage [4], because thicker straw layer more absorbed rasp bar strokes.

\subsection{Grain cleanliness}

The corn ear threshing investigation considered the different shapes of filler plates used to cover cylinder spaces between the rasp bars, with the aim of examining their effect on the proportion of impurities separated through individual sections of the concave. The proportion of impurities in the grains separated through concave determines the load of the combine-harvester's cleaning shoe [17]. The investigation showed that there was no significant difference in the proportion of impurities that fell through the concave grating (Table 1) regardless of the shape of the threshing cylinder's spaces between the rasp bars.

Table 1

Effect of the shape of cylinder spaces between rasp bars on the proportion of impurities $(P, \mathrm{~g})$ in the mass separated through the concave

\begin{tabular}{|l|l|l|l|}
\hline Cylinder spaces between rasp the bars & $\begin{array}{l}\text { Section } 1 \text { of the concave } \\
P_{1}, \mathrm{~g}\end{array}$ & $\begin{array}{l}\text { Section } 2 \text { of the concave } \\
P_{2}, \mathrm{~g}\end{array}$ & $\begin{array}{l}\text { Section } 3 \text { of the concave } \\
P_{3}, \mathrm{~g}\end{array}$ \\
\hline Open threshing cylinder & $2.04 \pm 0.51$ & $1.01 \pm 0.21$ & $1.83 \pm 0.67$ \\
\hline Cylinder covered with set FP-I & $2.03 \pm 0.45$ & $1.33 \pm 0.40$ & $2.14 \pm 0.91$ \\
\hline Cylinder covered with set FP-II & $2.75 \pm 0.52$ & $1.54 \pm 0.34$ & $2.15 \pm 0.78$ \\
\hline Cylinder covered with set FP-III & $2.36 \pm 0.57$ & $1.51 \pm 0.60$ & $2.49 \pm 1.20$ \\
\hline
\end{tabular}

\subsection{Average length of crushed cobs}

In the course of threshing, corn ears suffer from impacts with the rasp bars. As a result of these impacts, not only do corn grains separate from the cobs of corn ears, but the cobs are also crushed, causing their smallest parts to fall through the concave holes while the remainder are passed onto the straw walkers. Excessive cylinder speed and tight clearances between the cylinder and the concave can lead to split corn grain and excessive cob breakage [13]. Too many broken cobs can lead to overwhelm the cleaning shoe [3]. It was also found that threshing losses consisted primarily of broken cobs with kernels still attached [13].

Investigation of corn ear threshing under varied feed rates over the range of $4 \mathrm{~kg} \mathrm{~s}^{-1}$ to $12 \mathrm{~kg} \mathrm{~s}^{-1}$ using threshing cylinders with different filler plate shapes allowed us to look into their effect on the crushing of corn cobs. Accordingly, corn cobs were found to be crushed most when FP-II was used, resulting to an average corn cob length $l$ of $76.9 \pm 5.1 \mathrm{~mm}$. Corn cobs were crushed least when the threshing cylinder featuring the standard space shape between the rasp bars was used, resulting to an average corn cob length of $82.4 \pm 5.4 \mathrm{~mm}$. However, no significant difference in corn cob length in relation to the shape of the spaces between the rasp bars was observed. Moreover, feed rate had no significant effect on cob length within the threshing unit.

\section{Conclusions}

1. Investigation of corn ear threshing showed that the shape of spaces between the cylinder rasp bars had a significant effect on the intensity of grain separation through the concave. An increased feed rate not only resulted in increased grain separation intensity but also increased the influence of the shape of the spaces between the cylinder rasp bars. Grain separation was found to be most intensive when the threshing cylinder was covered with set FP-III at a $12 \mathrm{~kg} \mathrm{~s}^{-1}$ feed rate, resulting to a grain separation intensity of $7.42 \mathrm{~kg} \mathrm{~s}^{-1}$.

2. A comparative analysis of the effect of the shape of the spaces between the rasp bars on threshing loss showed that a minimum loss of $1.31 \%$ was suffered at a feed rate of $12 \mathrm{~kg} \mathrm{~s}^{-1}$ when the threshing cylinder covered with set FP-III was used. The maximum grain loss (1.80\%) was observed when the open threshing cylinder was used at the same feed rate $q$. Overall, the findings of this investigation show that the least threshing loss, i.e., $0.16 \%$, was suffered at a feed rate of $4 \mathrm{~kg} \mathrm{~s}^{-1}$ when the threshing cylinder was covered with set FP-III.

3. Findings of the corn ear threshing investigation involving different shapes of spaces between the threshing cylinder rasp bars showed that with increasing feed rate $q$, the portion of grain passed onto the straw walkers $K$ tended to increase. At a feed rate of $12 \mathrm{~kg} \mathrm{~s}^{-1}$, the lowest percentage of grain passed onto the straw walkers $(23.0 \%)$ was achieved when the threshing cylinder covered with set FPIII was used; the maximum percentage $(30.6 \%)$ was observed when the open threshing cylinder was used.

4. To summarize the grain damage data with respect to the entire threshing unit, grains were found to be damaged least when the threshing cylinder was covered with set FP-III. The reason for this is considered to be the rapid grain separation through the front portion of the concave. 


\section{References}

1. Tarighi, J.; Mahmoudi, A.; Alavi, N. 2011. Some mechanical and physical properties of corn seed (Var DCC 370), African Journal of Agricultural Research 6(16): 3691-3699.

http://dx.doi.org/10.5897/AJAR10.521.

2. Poničan, J.; Angelovič, M.; Jech, J.; Žitňák, M.; Findura, P. 2009. The effect of the design concept of combine harvester threshing mechanism on the maize crop threshing quality, Contemporary Agricultural Engineering 35(4): 268-274.

3. Petkevichius, S.; Shpokas, L.; Kutzbach, H.D. 2008. Investigation of the maize ear threshing process, Biosystems Engineering 99: 532-539.

http://dx.doi.org/10.1016/j.biosystemseng.2008.01.002.

4. Špokas, L.; Adamčuk, V.; Bulgakov, V.; Nozdrovický, L. 2016. The experimental research of combine harvesters, Research in Agricultural Engineering 62 (3): 106-112. http://dx.doi.org/10.17221/16/2015-RAE.

5. Mümken, P.; Baumgarten, J.; Böttinger, S. 2012. Basics for tangential threshing devices - mathematical description of the curve characteristic of the concave clearance, Landtechnik 67(1): 26-30.

6. Kuzin, G.A. 2005. Alternative threshing: the direction of improvement of the harvester, Vestnik Donskogo Gos Uni 5: 683-691 (in Russian).

7. Kuzin, G.A.; Pyatnitskaya, O.A.; Pakhomov, A.Y. 2009. Rational parameters of reflecting surface of enclosed threshing drum, State and Prospects of Development of Agricultural Engineering. Rostov-on-Don: 42-44 (in Russian).

8. Derevenko, V.V.; Severin, Y.D. 1991. Machines for harvesting of grain crops: theory and calculation. Krasnodar: Publishing Kuban Agrarian University. 145p. (in Russian).

9. Kiniulis, V.; Steponavičius, D.; Jasinskas, A.; Andriušis, A.; Jovarauskas, D.; Juknevičius, D. 2016. Combine harvester threshing cylinder constructive parameters. In: Kovačev, I. (ed.). Actual Tasks on Agricultural Engineering: Proceedings of the $44^{\text {th }}$ International Symposium on Agricultural Engineering, Opatija, Croatia: 143-153.

10. Kuzin, G.A.; Pakhomov, A.Y.; Pyatnitskaya, O.A.; Tsordanidi, G.G. 2010. Alternative threshing: the direction of improving harvesting techniques, Innovation, Ecology and Resource-saving Technologies in the Enterprises of Mechanical Engineering, Aviation, Transport and Agriculture. Rostov-on-Don: 224-234 (in Russian).

11. Pužauskas, E.; Steponavičius, D., Jotautienè, E., Petkevičius, S., Kemzūraitė, A. 2016. Substantiation of concave crossbars shape for corn ears threshing, Mechanika 22(6): 553-561. http://dx.doi.org/10.5755/j01.mech.22.6.16370.

12. Yu, Y.; Yu, J.; Li, Q.; Yu, J.; Fu, H. 2013. Analysis on the contact interaction between thresher and corn ears based on the DEM, Applied Mechanics and Materials 246-247: 71-77.

http://dx.doi.org/10.4028/www.scientific.net/AMM.246 -247.71 .

13. Paulsen, M.R.; Pinto, F.A.C.; de Sena Jr., D.G.; Zandonadi, R.S., Ruffato, S.; Gomide Costa, A.;
Ragagnin, V.A.; Danao, M.-G.C. 2014. Measurement of combine losses for corn and soybeans in Brazil, Applied Engineering in Agriculture 30(6): 841-855.

http://dx.doi.org/10.13031/aea.30.10360.

14. Chen, D.; Kang, F.; Zhu, Q.; Wang, S. 2012. Study on combine harvester speed control based on optimum threshing power consumption model, Applied Mechanics and Materials 130-134: 1911-1914.

http://dx.doi.org/10.4028/www.scietific.net/AMM.130134.1911.

15. Pishgar-Komleh, S.H.; Keyhani, A.; MostofiSarkari, M.R.; Jafari, A. 2013. Assessment and determination of seed corn combine harvesting losses and energy consumption, Elixir Agriculture 54: 1263112637.

16. Li, X.P.; Wu, K. 2016. Design and experiment of bionic discrete devices based on corn threshing system, Chemical Engineering Transactions 51: 127-132. http://dx.doi.org/10.3303/CET1651022.

17. Li, X. 2013. Study on relationship of feeding form and threshing-cleaning rate of corn ears, Advanced Material Research 753-755: 1462-1466.

http://dx.doi.org/10.4028/www.scietific.net/AMR.753755.1462 .

V. Kiniulis, D. Steponavičius, A. Andriušis, A. Kemzūraitè , D. Jovarauskas

\section{CORN EAR THRESHING PERFORMANCE OF FILLER-PLATE-COVERED THRESHING CYLINDERS}

S u m m a r y

The aim of the study was to determine the influence of threshing cylinder filler plates on threshing and grain separation losses, grain separation intensity through concave and grain damage. The comparative corn ear threshing experiments were performed using an open (conventional) threshing cylinder; filler plate I (FP-I) with a shape resembling the standard shape of the cylinder spaces between adjacent rasp bars; filler plate II (FP-II) with a working plane at an angle of $55^{\circ}$ to the radius of the cylinder; and filler plate III (FP-III) with a working plane at an angle of $36^{\circ}$ to the radius of the cylinder. Feed rates varied from $4 \mathrm{~kg} \mathrm{~s}^{-1}$ to $12 \mathrm{~kg} \mathrm{~s}^{-1}$. An increased feed rate resulted in increased the influence of the shape of the spaces between the cylinder rasp bars. Grain separation was found to be most intensive when the threshing cylinder was covered with set FP-III at a $12 \mathrm{~kg} \mathrm{~s}^{-1}$ feed rate. An increase in feed rate caused grain loss to increase too. The least threshing loss was suffered at a feed rate of $4 \mathrm{~kg} \mathrm{~s}^{-1}$ when the threshing cylinder was covered with set FP-III. To summarize the grain damage data with respect to the entire threshing unit, grains were found to be damaged least when the threshing cylinder was covered with set FP-III.

Keywords: threshing loss, grain separation intensity, grain damage, feed rate, threshing cylinder design.

Received January 19, 2017 Accepted October 13, 2017 